\title{
Twin principles for need-based attendance policy in undergraduate medical education
}

\author{
Santosh Kumar, Zayabalaradjane Zayapragassarazan and Kadambari Dharanipragada \\ Department of Medical Education, Jawaharlal Institute of Postgraduate Medical Education and Research, \\ Puducherry, India
}

\section{Introduction}

Twin principles of attendance policy are suggested to understand need-based attendance policies reported in literature for undergraduate medical education. In these reports, clinical sessions need compulsory attendance with remediation, nonclinical small group sessions need compulsory attendance with minimum attendance requirement and lectures need either compulsory or noncompulsory attendance. Twin principles can be used to identify sessions needing compulsory or non-compulsory attendance.

\section{Twin principles of attendance policy}

Twin principles of attendance policy are as follows. (1) First twin principle is that "a session which has no alternative learning method should have compulsory attendance." This principle applies to clinical sessions and non-clinical small group sessions which are dis- cussed later. This principle can also apply to some types of lectures which are also discussed later. (2) Second twin principle is that "a session which has an alternative learning method should have non-compulsory attendance." This principle applies to traditional/didactic lectures which are discussed later.

The idea of suggested first principle of attendance policy is given in literature in various forms. Thus compulsory attendance is suggested for "which cannot be mastered by text book or online teaching material" [1], "which cannot be acquired in other ways" [2], and "that could not be easily reproduced outside the curriculum" [3]. The suggested first principle has presented these ideas in a usable form. The suggested second principle complements the first principle. The twin principles of attendance policy provide conceptual basis for identifying sessions which require either compulsory or noncompulsory attendance.
Received: August 13, 2018 • Accepted: October 2, 2018

Corresponding Author: Zayabalaradjane Zayapragassarazan (https://orcid.org/0000-0002-8728-4047) Department of Medical Education, Jawaharlal Institute of Postgraduate Medical Education and Research, Puducherry-605006, India

Tel: +91.4132355169 Fax: +91.4132355169 email: zprazan@yahoo.co.in
Korean J Med Educ 2018 Dec; 30(4): 369-372.

https://doi.org/10.3946/kjme.2018.112

eISSN: 2005-7288

(C) The Korean Society of Medical Education. All rights reserved. This is an open-access article distributed under the terms of the Creative Commons Attribution Non-Commercial License (http:// creativecommons.org/licenses/by-nc/3.0/), which permits unrestricted non-commercial use, distribution, and reproduction in any medium, provided the original work is properly cited. 


\section{Need-based attendance policy for clinical sessions}

Clinical sessions are situations in which students learn through contact with patients. It is universally agreed that patient contact is essential for learning patient care skills and competencies including history taking, physical examination, listing differential diagnoses, choosing investigations, and diagnosing and treating and related skills and competencies of communication, professionalism, and collaboration. Learning through contact with patients is included in the top 'does' level of Miller's triangle which involves real life experiences. Experiential learning involves four steps of concrete experience, observation and reflection, abstract conceptualization, and using concepts in new situations which form Kolb's experiential learning cycle. Experiential learning cycle needs to be repeated as many times as possible for effective learning of patient care skills and competencies using patient contact. To fulfill this need compulsory attendance policy with provision for appropriate remediation or make up for missed sessions is required for clinical sessions. The rationale for using this attendance policy in clinical sessions is that there is no other alternative method for learning patient care skills and competencies. This necessitates compulsory attendance for clinical sessions as per the first principle of attendance policy. Another reason for using compulsory attendance policy is that mandatory attendance reduces student absenteeism [4].

As an example, in stage 3 (including years 3 and 4) of Sydney Medical Progarmme of Sydney Medical School "attendance is required at all clinical activities" and remediation is needed for missed activities [1]. Clinical activities include 'direct patient-centered' activities (bedside clinics, ward rounds, ward work, seminars, or lectures in which patients are present) and SCORPIOs (structured clinical objective referenced problemoriented integrated organized clinical sessions). Simulation sessions for skill learning ('shows how' level of Miller's triangle) and formative or summative assessment sessions in classroom and workplace are also included in clinical activities. In another example, in phase 2 (including years 3 and 4) of medical programme of the University of Queensland '100\% attendance is expected for all clinical placement days' and 'students must make up any clinical placement days missed ...' [5]. Make up sessions include additional clinical experience 'out-ofhours and on weekends.'

\section{Need-based attendance policy for non- clinical small group sessions}

Nonclinical small group sessions include practical sessions, tutorials, seminars, problem-based learning sessions, and workshops. These small group sessions are essential for collaborative learning which facilitates development of skills such as listening and teamwork and attitudes such as respect and cooperation [6]. Learning of these skills and attitudes in small groups is based on Kolb's experiential learning principles and needs repetition of experiential learning cycle again and again for their effective learning. In order to fulfill this need compulsory attendance policy is required for nonclinical small group sessions. As there is no alternative method for collaborative learning, compulsory attendance policy is justified for nonclinical small group sessions according to the first principle of attendance policy. As mandatory attendance reduces student absenteeism there is further justification for compulsory attendance policy [4]. The use of compulsory attendance policy for nonclinical small group sessions is reported in literature [1-3]. In stage 1 (year 1) and stage 2 (year 2) of Sydney Medical Programme of Sydney Medical School, 'required learning activities' include small group 
sessions such as practical classes; problem-based learning sessions; and workshops on personal and professional development and research [1]. Minimum attendance requirement is $80 \%$ of 'required learning activities.' In a report from India, minimum attendance requirement was increased from $75 \%$ to $90 \%$ for phase I (first 2 and a half years) of MBBS (Bachelor of Medicine and Bachelor of Surgery) program which included problem-based learning sessions [7]. Student absenteeism was reduced by increasing minimum attendance requirement.

\section{Need-based attendance policy for lectures}

The attendance policy for lectures is debatable [8]. In some programs lectures have compulsory attendance and in others lectures are non-compulsory [9]. Majority of medical students prefer non-compulsory attendance for lectures [8,9].

Twin principles of attendance policy can be applied for lectures. Uniform attendance policy may not be justifiable for all lectures. Lectures which have the presence of patients (as in demonstrations) and which have small group sessions (as in team-based learning) should have compulsory attendance. This is justified according to the first principle of attendance policy because there is no alternative learning method for these situations. An example of compulsory attendance for lectures having the presence of patients is provided earlier [1]. With compulsory attendance policy for lectures, minimum attendance requirement can be kept at $90 \%$ as was reported in a Indian study involving students of first 2 and a half years of the undergraduate medical educational program [7]. Other lectures can have compulsory attendance if lecture recordings are not officially provided to students and non-compulsory attendance if lecture recordings are given to students as part of the curriculum. Lecture recordings are alternative learning method and according to the second principle of attendance policy non-compulsory attendance is justified. It is emphasized that non-compulsory attendance policy is not no-attendance policy. Live lectures are continued to be held when lecture recordings are provided to students. As an example of non-compulsory attendance policy the lectures for first-year medical students of the University of Massachusetts Medical School were not required and students were provided recordings for at least $95 \%$ of lectures, slides and other electronic materials [10]. In this example lecture attendance ranged from $65 \%$ to $95 \%$. Most students made deliberate choice for attending lectures based on "previous experience with the lecturer, predictions of what would occur during the session itself, personal learning preferences, and learning needs at that particular time, with the overriding goal of maximizing learning" [10]. The authors concluded that fears of negative effect of e-learning resource on attendance in lecture appeared without any basis.

\section{Conclusions}

Twin principles of attendance policy explain the rationale of using need-based attendance policies for different educational sessions. It is suggested that these principles can be used for identifying sessions needing compulsory or non-compulsory attendance.

\section{ORCID:}

Santosh Kumar: https://orcid.org/0000-0002-9002-0552; Zayabalaradjane Zayapragassarazan: https://orcid.org/0000-0002-8728-4047; Kadambari Dharanipragada: https://orcid.org/0000-0001-6375-6751

Acknowledgements: None.

Funding: None. 
Conflicts of interest: No potential conflict of interest relevant to this article was reported.

Author contributions: Literature search, analysis and interpretation of literature: SK, ZZ; drafting the article: SK, ZZ; critical revision of the article: ZZ, KD; and final approval of the version to be published: SK, ZZ, KD.

\section{References}

1. The University of Sydney. Sydney Medical SchoolSydney Medical Program attendance provisions 2016. http://sydney.edu.au/policies/showdoc.aspx?recnum=PD OC2015/399\&RendNum=0. Published 2016. Accessed March 5, 2018.

2. The University of Queensland, Australia. Faculty of medicine: MD program: attendance guidelines-phase 1. https://medicine-program.uq.edu.au/files/2912/Phasel-Att endance-Guidelines-20170309.pdf. Accessed March 5, 2018.

3. Damant R, Rourke L, Wilson B, et al. Medical school attendance is significantly lower in preclinical students who are experiencing psychological distress. MedEdPublish. 2016. https://doi.org/10.15694/mep.2016.000002.
4. Marburger DR. Does mandatory attendance improve student performance? J Econ Educ. 2006;37(2):148-155.

5. The University of Queensland, Australia. Faculty of medicine: medical program: attendance guidelines-phase 2. https://medicine-program.uq.edu.au/files/3416/Phase2Attendance-Guidelines.pdf. Accessed March 5, 2018.

6. Wood D. Collaborative learning. In: Cantillon P, Wood $\mathrm{D}$, eds. $\mathrm{ABC}$ of Learning and Teaching in Medicine. West Sussex, UK: Wiley-Blackwell; 2010:10-14.

7. Subramaniam B, Hande S, Komattil R. Attendance and achievement in medicine: investigating the impact of attendance policies on academic performance of medical students. Ann Med Health Sci Res. 2013;3(2):202-205.

8. Daud A, Bagria A, Shah K, Puryer J. Should undergraduate lectures be compulsory?: the views of dental and medical students from a UK university. Dent J (Basel). 2017;5(2): E15. https://doi.org/10.3390/dj5020015.

9. British Medical Association. Students decide: should lectures be compulsory? Published February 2018. https://www.bma.org.uk/news/2012/may/students-decideshould-lectures-be-compulsory. Accessed March 5, 2018.

10. Billings-Gagliardi S, Mazor KM. Student decisions about lecture attendance: do electronic course materials matter? Acad Med. 2007;82(10 Suppl):S73-S76. 